\title{
PRESENCIA TROVADORESCA EN LA CORONA DE ARAGÓN
}

ISABEL DE RIQUER

Universitat de Barcelona

La presencia de trovadores provenzales en la Corona de Aragón fue continua desde los comienzos de este movimiento poético; y fueron los reyes catalanes los que acogieron en su corte a los últimos de estos profesionales. La proximidad geográfica, la afinidad lingüística y las relaciones feudales y matrimoniales entre las casas señoriales de ambos lados de los Pirineos facilitaron esta precoz e intensa comunicación, iniciada y mantenida por la Casa real, pues los reyes de Aragón, condes de Barcelona fueron, también, a partir de 1166, marqueses de Provenza.

Marcabrú, el primer trovador de oficio conocido, fue el primero de los trovadores provenzales que visitaron Cataluña, después de haber pasado por la corte de Alfonso VII de León. En el ambiente del conde de Barcelona Raimon Berenguer IV, compuso en 1149 el Vers del lavador, importante y personalísima canción de cruzada para animar a los príncipes cristianos a participar en la Reconquista española [Los trovadores I, 206]' ${ }^{1}$ El arte de Marcabrú es requerido, pues, con una finalidad práctica y urgente y con evidente función de arenga. En otras de sus obras este trovador gascón seguirá interesado por los asuntos peninsulares, como demuestra en las dos o tres breves pero adecuadas alusiones a la situación política y militar de Lérida y de Barcelona, o en los saludos que envía a la ciudad condal,

\footnotetext{
'Las citas de los trovadores pertenecen a M. de RIQUER, Los trovadores. Historia literaria y textos, 3 vols., Barcelona, Planeta, 1975 y sucesivas reimpresiones, y en su defecto a la edición correspondiente.

"Anuario de Estudios Medievales". 26 (1996)
} 


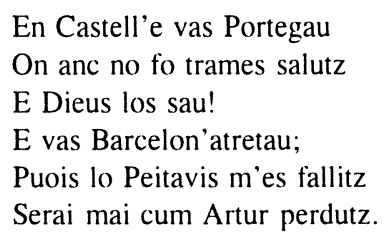

[En Castilla y hacia Portugal donde nunca fueron enviados saludos, (les digo)! Dios les salve!, y a Barcelona lo mismo; pues, desde que el Peitavino ${ }^{2}$ me falta, estaré perdido para siempre como Arturo]. Al prim, 293,4 vv.58-63, [Dejeanne 1971, 16].

Hacia 1170, es cuando aparece un movimiento trovadoresco de origen catalán, que no asume un carácter autónomo sino que estará orientado, en los géneros, conceptos y esquemas métricos por los trovadores del otro lado de los Pirineos para los que Cataluña será una meta literaria activa y atrayente. A partir de estos años habrá en Cataluña trovadores catalanes, juglares catalanes, protectores de trovadores catalanes y un público catalán. No nos ha de extrañar pues que este ambiente de saturación lírica se expansione con los años y se forme en él un centro de interés hacia la composición de poéticas en lengua vulgar tan tempranas como las Razós de trobar de Ramon Vidal de Besalú de principios del siglo XIII, y que las novas rimadas de este mismo escritor reflejen el ambiente trovadoresco de las cortes catalanas [I. de Riquer 1989-1990; Tavani 1995; Calzolari 1995].

Los trovadores más relevantes de este «medio siglo de oro» de la lírica trovadoresca (1162-1213), que coincide con el reinado de Alfonso II y con el de su hijo Pedro II, por lo que también ha sido llamado "período alfonsí" [Frank 1955], visitaron las cortes del monarca catalán y todos alaban en sus canciones su generosidad y le recuerdan con nostalgia después de su muerte.

Qu'anc non estey jorn d'Arago que $\cdot$ l saut/ no.y volgues ir,... [Pues nunca estuve un día (ausente) de Aragón sin querer ir allí a toda prisa], dice el gran trovador Arnaut Daniel en L'aur'amara, 29,13 vv.41-42 [Los trovadores II, 627].

De Peire Vidal, el más español de todos los trovadores provenzales, según Hoepffner [1946], y, podríamos añadir, también el más catalán de

\footnotetext{
${ }^{2}$ Guillermo VIII de Poitiers, X duque de Aquitania (1126-1137), hijo del primer trovador conocido Guilhem de Peitieu, fue sin duda el más antiguo protector de Marcabrú.
} 
todos ellos, se dice en una razó que era el rey Alfonso el que le animaba y le urgía a componer: "Y el rey le empezó a rogar, y también todos los demás barones (del séquito del rey, nobles catalanes y aragoneses), que tenía que hacer una canción que ellos llevarían a Aragón. Tanto le rogaron el rey y sus barones que él dijo que se alegraría y que dejaría el duelo, y que compondría una canción y lo que el rey quisiera, ...», De chantar m'era laissatz/ per ira e per dolor ...364,16 [Los trovadores II, 897]. Los topónimos catalanes, Cervera, Vic, Montjuic, Barcelona y Balaguer, salpican sus canciones; y toda la familia real recibe el homenaje poético de Peire Vidal: el rey, su mujer Sancha de Castilla, su hijo Pedro II y sus hijas Constanza y Leonor. Y cuando muere el monarca Peire Vidal compone la canción: Ben viu a gran dolor/ qui pert son bon senhor, / Qu'eu perdei lo melhor/ Qu'anc mortz pogues aucir. [Con gran dolor vive quien pierde a su buen señor, pues yo perdí al mejor que la muerte ha podido matar]364,13 vv.1-4 [Anglade 1966 ${ }^{23}, 118$ ].

Este grupo de trovadores, unos veinte [Cluzel 1957-58], que se agruparon en años sucesivos en torno al rey Alfonso o que desde lejos le nombraron en sus canciones, se convirtieron en defensores de su política ultrapirenaica, sobre todo frente a las pretensiones del conde de Tolosa. Sus canciones fueron una excelente campaña de opinión favorable al rey, lo que no es óbice para que en otros momentos se mostraran severos ante determinadas actitudes del monarca respecto a la aristocracia feudal, aunque nunca con el tono tan duro y hostil de Bertran de Born y de Guiraut del Luc que le tildan de reis apostiz, "rey postizo", [Ruiz Domènec 1996, 123-129] ni, sobre todo, con la violencia de Guillem de Berguedà [M. de Riquer 1959].

Todo ello permite considerar a los trovadores provenzales desde otra óptica que la de autores de canciones de amor y exponentes del lujo y la cultura de una sociedad, sino como partícipes y cronistas de los acontecimientos históricos y domésticos de su tiempo. Las canciones de estos trovadores surgen, por tanto, de una situación concreta y como han de componerse y divulgarse enseguida para mantener viva su actualidad, los autores se sirven del estrofismo y de la melodía de una canción ya conocida que facilita su creación y divulgación y que no presenta dificultades para ser recordada y repetida por todos. Algunas revelan aspectos tan particulares de un preciso momento que cuesta, ahora, su total interpretación; o, en otras, no aparece el nombre del rey o del príncipe a quien va dedicada la canción, porque el trovador está en su misma corte, componiéndola y cantándola 
delante de él ${ }^{3}$. El sirventés se convierte, por tanto, en eficaz instrumento de difusión de las ideas del momento y si por una parte es efímero por otra constituye un precioso testimonio histórico. Este ambiente poético y político a la vez que está utilizando el rey Alfonso de Aragón con éxito, le anima, para crearse una opinión favorable entre sus súbditos ultrapirenaicos, a cultivar por él mismo la lírica trovadoresca hacia la que indudablemente también tenía un interés personal [M. de Riquer 1959]. Que a Alfonso II, rey de Aragón, conde de Barcelona y marqués de Provenza, su Vida provenzal lo llame aquel que trobet es lo suficientemente indicativo. Era biznieto por línea materna de Guilhem de Peitieu, el primer trovador conocido, y su mayor orgullo fue destacar en esta actividad literaria difícil y prestigiosa. Sólo se conservan dos canciones del rey Alfonso, una cansó, dentro del tono más estrictamente ortodoxo de la fin'amor trovadoresca, de esquema métrico único y sin rasgos de catalanismos, y la tensó, debate poético que debió tener lugar en los últimos meses del año 1170, y en algún lugar de sus dominios, con el trovador más importante del momento, Giraut de Bornelh, mestre de trobadors, $\mathrm{y}$, con toda probabilidad, mestre también del rey [Los trovadores I, 566].

Pasemos de la época dorada del rey Alfonso de Aragón a la segunda mitad del siglo XIII, el final de la actividad trovadoresca, para hablar de su nieto, Jaime I y de los trovadores y juglares, también más de veinte, que frecuentaron su corte, o que, desde otros lugares le dirigieron sus versos, entre 1213 aproximadamente y 1276, año del fallecimiento del rey. Algunas de sus canciones son de amor y sólo se alude al monarca en unos pocos versos o en la tornada o envío, otras recogen con precisión acontecimientos de la vida política y social del rey catalán y su entorno.

Desde las primeras incursiones de las tropas del rey de Francia en los señoríos del Sur los provenzales habían dirigido peticiones de ayuda al rey Pedro II tras su matrimonio con María de Montpellier en 1204.

Peire de Bergerac, después de tres estrofas que contienen un elogio de la guerra al estilo de los de Bertran de Born, se dirige a Pedro II de manera directa para que intervenga en la rebelión de Montpellier de 1206 [Milá y Fontanals 1966,131-132; Chambers 1979; Aurell 1989, 75-76],

${ }^{3}$ Este es un aspecto que sigue produciendo controversias entre los investigadores. Por citar sólo un caso de la misma época y ambiente que ahora nos ocupa, ¿a qué rey catalán va dedicado el Jaufré? ¿A Alfonso III, Pedro II o a Jaime I? 


\author{
E si.l bos reis d'Arago \\ Conquer en breu sazo \\ Monpeslier ni fai deman, \\ Eu non plaing l'anta ni dan \\ D'en Guillem, car es savais, \\ $\mathrm{Ni} \cdot \mathrm{n}$ tem lo seignor del Bais, \\ Anz mou tal ais, \\ Per la fe que dei a vos, \\ No sai si l'er danz o pros.
}

[Y si el buen rey de Aragón reclama y conquista en breve Montpellier, no lamento la vergüenza ni el daño de Guillermo, porque es cobarde, ni temo al señor del Baus, antes lanzaré tal grito que, por la fidelidad que os debo, no sé si será bueno o malo para él]. Bel m'es cant aug lo resso, 329,1, vv. $28-36^{4}$.

Del mismo modo le interpela Bernart Arnaut de Moncuc en un sirventés, de esquema métrico único, que bien se podría denominar sirventés-cansó [Köhler 1969] porque los seis últimos versos de cada estrofa contienen delicadas expresiones amorosas
Man caval corssier
Veirem vas Tarzana
Devas Balaguier
Del pros rey qu's vana
C'a pretz a sobrier
Venra ses falhensa
Lay en Carcasses,
Mas ges gran temensa
No.n an li Franses.
Mas ieu n'ai
De vos sai,
Dona, que m'esglai
Lo dezir qu'ieu n'ay
Del vostre bel cors cortes
Complit de totz bes.

[Veremos muchos corceles del noble rey, que se envanece de que tiene mérito en demasía, en Tarzana (?) hacia Balaguer. Sin fallo alguno vendrá al Carcasés, aunque los Franceses no tienen por ello gran temor. Pero yo

${ }^{4}$ Texto de Milá y Fontanals. Para Guillem IV de Forcalquier y Guillem des Baux, véase AURELl 1989, pp. 69-76. 
lo tengo de vos, Señora, pues me estremece el deseo que siento de vuestro bello y noble cuerpo, completo de todo bien]. Er can li rozier, 55,1, vv.1630 [Chambers 1979].

Tras la derrota de Muret en 1213, los trovadores reclamaban otra vez más la atención de los monarcas catalanes en la situación política de Provenza. El tolosano Guilhem Anelier veía en el joven Jaime I la esperanza de los provenzales como lo habían sido sus antecesores, y en un sirventés pedía a Dios que le concediera fuerza suficiente,

\author{
Don prec Ieshu Crist que poder \\ li don e qu'el garde, si'l play, \\ que clerx no'l puescon dan tener \\ ab fals prezics totz ples d'esglay, \\ quar tant es grans lur trichamen \\ qu'el fuecx enfernals plus preon \\ ardran, quar volon tant argen \\ qu'hom peccaire fan cast e mon. \\ A la gleiza falh son saber, \\ quar vol los Frances metre lay \\ on non an dreg.
}

\begin{abstract}
[Por lo que ruego a Jesucristo que le dé poder y le guarde, si le place, para que los clérigos no le hagan daño con sus falsos y estremecedores sermones, pues tantos son sus engaños que arderán en el fuego más profundo del infierno, pues les gusta tanto el dinero que absuelven a los pecadores (ricos). La Iglesia carece de sabiduría pues quiere poner a los franceses en donde no tienen derecho a estar.] 204, [Raynouard Choix IV, 274]
\end{abstract}

Animados por la victoria, los franceses, es decir la tropas del rey de Francia, habían vuelto a encaminarse hacia el sur, disfrazando los saqueos, los incendios y los combates con la excusa de cruzada contra la herejía albigense. Y aunque a costa de grandes pérdidas la primera incursión fue rechazada, en 1226 con la conquista de Aviñón y de Tolosa y la anexión a la corona francesa de diversos principados, el dominio francés fue ya un hecho. Los provenzales se dirigen, otra vez, a Jaime I reclamando su ayuda; $\mathrm{y}$, trovadores de gran prestigio y otros menos conocidos, pero cuyas composiciones han conservado los cancioneros, escriben duros sirventeses para empujar al monarca catalán en esta empresa. 
En la Vida de los trovadores Tomier y Palaizí se dice que hacían «sirventeses sobre el rey de Aragón, sobre los condes de Provenza y de Tolosa y sobre el de los Baus, y sobre los asuntos que circulaban por Provenza. Y fueron dos caballeros de Tarascón, amados y apreciados por los buenos caballeros y por las damas» [Los trovadores II, 1154-1160]. Son dos los sirventeses compuestos por estos caballeros-trovadores para animar a los provenzales a combatir las huestes de Simón de Monfort. En uno de ellos conminan a resistir los aviñoneses que padecían el asedio de las tropas de Luis VIII de Francia, a la vez que piden ayuda al emperador de Alemania y a Jaime I:

\author{
Els Arragones \\ ai perdut ma poigna \\ e mon sirventes \\ et en Cathaloigna: \\ e 1 reis q'es joves \\ no.l troba qi.l pogna. \\ Segur estem, seignors, \\ e ferm de ric socors.
}

[Con los Aragoneses y los catalanes he perdido mi sirventés y mis fuerzas.

El rey, que es joven, no encuentra quien le empuje. Mantengámonos firmes, señores, y contemos con un poderoso socorro]. De chantar farai, 442,1, vv. 25-32. [Aurell 1989,257].

El trovador Sordel de Goito (...1220-1269...) cuando, en 1230, residía en la corte de Ramon Berenguer $\mathrm{V}$ compuso un sirventés en la que elogiaba a «tres príncipes desheredados», uno de los cuales era Jaime I,

\author{
Nostre reis d'Aragon, be $m$ platç \\ car gient es Amilhau cobratç, \\ q'el ac ab vasalagie;
}

[(de) nuestro rey de Aragón, bien me place, porque bien ha recobrado Millau lográndolo valerosamente]. Pois mo $m$ tenc, 37,25 vv.16-18 (Boni $1954,123)]$.

$Y$ en el magnífico planh que compuso en 1236 por la muerte del gran señor, trovador y protector de trovadores Blacatz d'Alms, elogia Sordel al difunto imaginando que su corazón es repartido entre los soberanos contemporáneos para que lo coman y así adquieran las virtudes que poseía 
Blacatz. El motivo literario del «corazón comido» tiene en este planh una revitalización ingeniosa y de gran fortuna posterior, también en ambientes catalanes ${ }^{5}$.

La estrofa del planh que Sordel dedica al rey Jaime I es la siguiente:

Del rey d'Arago vuelh del cor deia manjar,

que aisso lo fara de l'anta descarguar que pren sai de Marcella e d'Amilau; qu'onrar no.s pot estiers per ren que puesca dir ni far;

[Quiero que el rey de Aragón coma del corazón, pues ello lo hará descargar de la vergüenza que recibe aquí en Marsella y en Millau; porque de otro modo no puede honrarse por nada que pueda decir ni hacer;] Planher vuelh en Blacatz en aquest leugier so, 437,24, vv.25-28 [Los trovadores III, 1464].

El trovador Peire Duran,(o Duran Sartre de Paernas), que es probable que visitara la corte de Jaime I antes de 1239, critica el mayor interés del monarca catalán hacia la conquista de Valencia que a los asuntos provenzales.

«Pero, ¿cómo los aragoneses no abandonan su empresa contra el rey de Valencia para arrebatar a los franceses sus conquistas?» Vil sirventes, 126,2 [Milá y Fontanals 1966, 156-157].

$\mathrm{Y}$, en otro sirventés, insiste en sus denuestos al rey:

En talent ai qu'un sirventes encoc

Per trair' a cels qu'an mes pres a deroc

Quar mantenon no e han faidit hoc

$\ldots$

Tos temps serai malvolens et enics

Al rei Jacme que mal tenc sos afics,

Qu'el sagramen qu'el fei son mals e trics.

[Me anima el deseo de preparar un sirventés contra aquellos que han echado por tierra el mérito y mantienen el no y han desterrado el sí...Siempre veré con malevolencia y aversión al rey Jaime que tan mal mantiene su palabra y cuyos juramentos son falaces y engañosos]. En talent ai, 126,1 [Jeanroy 1904; Aurell 1989, 152].

${ }^{5}$ Véase I. de RiQuer y M. Simó TORRES, "Cor de dona, dolça vianda", en las "Mélanges Philippe Ménard" (en prensa). 
También lamenta el trovador Bertran de Born el Joven (...1179$1233 . .$.$) que los éxitos militares del rey sean contra el Islam y no contra los$ franceses

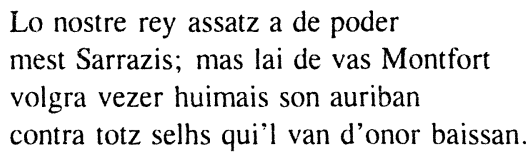

[Nuestro rey es muy poderoso entre los sarracenos, pero ahora quisiera ver su enseña en Montfort contra aquellos que rebajan su honor]. Un sirventes farai novelh, 81,1a vv.41-44 [Los trovadores II, 951;Aurell 1989,140 y $315]^{6}$.

El trovador Aimeric de Belenoi (..1216-1243...) compuso una canción de amor en la corte del rey Jaime I hacia 1238, cuya tornada va dedicada al monarca, reprochándole su actitud poco decidida en proseguir la política occitana de sus antecesores [Aurell 1989, 125].

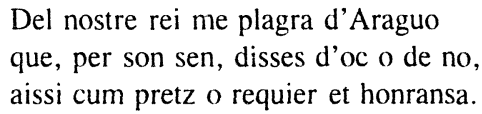

[Me gustaría que nuestro rey de Aragón dijera sí o no, según su juicio, tal como lo requieren mérito y honra.] Meravilh cum pot hom apelhar, 9,12, vv.41-43. [Los trovadores III, 1298].

Del trovador languedociano Bernart Sicart de Maruèjols sólo se conserva el sirventés, $A b$ greu cossire, dedicada a Jaime I,

Rey d'Arago si'us platz, per vos serai honratz.

[Rey de Aragón, si os place, seré honrado por vos]. Ab greu, 67,1, vv.7677 [Los trovadores III, 1203].

${ }^{6}$ No todos los críticos están de acuerdo en que este sirventés sea suyo; véase, Los trovadores, II, 951. 
Aprovecha este trovador el esquema métrico y las rimas, en la primera estrofa, de la famosa canción de Guillem de Cabestany, Lo dous cossire, 213,5, tan conocida en ambientes catalanes. El sirventés de Bernart Sicart "de tal interés histórico y hasta sentimental" [Los trovadores III, 1202] es una dura crítica a los franceses y a los caballeros de las órdenes del Hospital y del Temple y ataca a los clérigos con los términos y la intención empleados por otros trovadores desde el inicio de la guerra de los albigenses. Por las consideraciones políticas que se vierten en él parece que fue escrito en 1230 aunque nada hay que permita concluir si el trovador está en la corte del rey catalán o va a ir a ella.

Con un leve cambio, el trovador Peire Basc imitó esta composición en $A b$ greu cossire Et ab greu marrimen, también dedicada a Jaime el Conquistador.

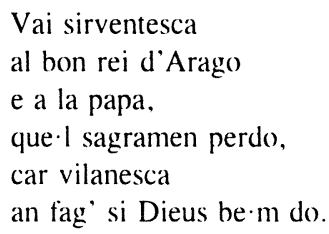

[Ve sirventés al buen rey de Aragón y al Papa para que le perdone el juramento, pues han cometido villanía, ¡vaya por Dios!]. 327,1 vv.61-66. [Appel, Prov. Inedita, 210].

No se puede saber si fueron sus méritos políticos o los poéticos los que hicieron que Jaime I en el Repartiment hecho después de la conquista de Valencia en 1238, asignara al trovador Guilhem de Montanhagol (...1238$1268 . .$.$) algunas tierras, en donde con toda probabilidad acabó su existencia$ después de 1268.

Con posterioridad a su primera estancia en los dominios del rey de Aragón, y residiendo en la corte de Raimon VII de Tolosa Guilhem de Montanhagol compuso, entre 1243 y 1249, algunos sirventeses en los que reclama la intervención de Jaime I después de que Provenza pasara a manos de Carlos de Anjou. 
quar si lus l'autre non ampara, major saut penran encara frances, ses temensa

[Si ahora el rey de Aragón no ataca, mucha será su abstinencia y lo mismo el conde a quien pertenece el Tolosanés (Raimon VII), pues ya no tiene salvación. Pues si el uno no ampara al otro los franceses sin temor darán un salto aún mayor]. Ges per malvestat qu'er veya. 222, 5. [Los trovadores III, 1430].

Y con uno de sus tan frecuentes juegos etimológicos lamenta que Proensa (proesa, proeza) se llamará a partir de ahora Falhensa (error).

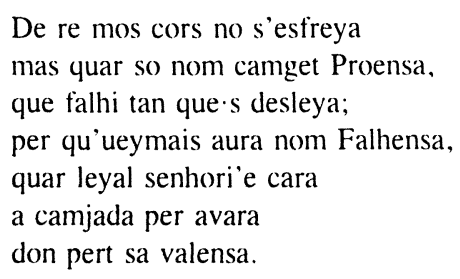

[Nada me horroriza tanto como el cambio del nombre de Provenza, que erró tanto que delinque, por lo que de ahora en adelante se llamará Error, pues ha cambiado una señoría leal y digna por otra avara, y ello le hace perder el valor].

También Bernat de Rovenac (..1242-1261...), que se mostró siempre muy duro en sus ataques a Jaime I, compone, a principios de 1242, un sirventés en el que hace un juego de palabras entre el verbo jazer y el nombre de Jacme:

Reis d’Aragó ses contenda deu ben nom aver Jacme, quar trop vol jazer, e qui que sa terra's prenda, el es tan flacs e chauzit que sol res no. i contraditz. 
[El rey de Aragón, sin discusión, debe llamarse Jaime pues quiere yacer demasiado y quienquiera que le tome su tierra, él es tan débil y tan indulgente, que en nade se le contradice] ${ }^{7} 66,3$, [Los trovadores III, 1570].

Las críticas al monarca catalán por parte de Bernart de Rovenac, se extendieron, años más tarde al infante Pedro, al que en Belh m'es quan vei, 66,1 , trata de verdugo porque hizo ahogar a uno de sus caballeros: qu'a filh de rei esta mal atrazag/ quant ampara nulh offici sag (que está ciertamente mal a un hijo de rey que aprenda el oficio de sayón) [Los trovadores, 1373].

La llegada de la casa de Francia a Provenza mediante una hábil política matrimonial, por la que Alfonso de Poitiers se intituló conde de Tolosa y Carlos de Anjou conde de Provenza, motivó que desde 1245 hasta 1262 se recrudecieran los enfrentamientos entre provenzales y franceses. A partir, pues, de 1246 empieza la tarea de los nuevos condes de Tolosa y de Provenza de "afrancesar" estos condados que fueron ocupados por un ejército no sólo de soldados sino de juristas y de administradores con la intención, entre otras, de imponer la lengua francesa. Estas actividades suscitaron la furiosa oposición de los provenzales que, aprovechando los dos años, 1247-1249, que pasó Carlos de Anjou en Egipto, militando en la cruzada organizada por su hermano el rey Luis IX, convocaron a los representantes de las ciudades de Aviñón, Arles y Marsella para constituir una alianza de defensa que había de durar cincuenta años y que fue un fracaso porque muchos de los grandes señores comprometidos en ella se pasaron a los franceses [Aurell 1989].

Por parte de los trovadores estos años tuvieron un eco poético considerable. Unos pocos, que se podrían calificar de "afrancesados", ponderaron en sus canciones a Carlos de Anjou y a su mujer Blanca de Provenza (aludida con el senhal de «Na Berengueira»), aunque, si examinamos detenidamente las tornadas de sus canciones, los elogios no dejan de ser consideraciones muy convencionales [A. Jeanroy, [1934] 1973 I, 331; S. Asperti 1995, 101].

Guiraut d'Espanha dice del nuevo conde de Provenza,

Pus era suy ab senhor

qu'es de plazen captenensa

\footnotetext{
1375

${ }^{7} \mathrm{Jac}$-me debe entenderse como "acuéstome" o "duérmome", véase Los trovadores, III, 1370-
} 


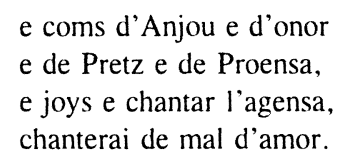

[Pues ahora estoy con un señor que es de amable condición y conde de Anjou, de honor, de mérito y de Provenza, y le agradan alegría y cantar, cantaré del mal de amor] 244,9, vv-1-6 [Hoby 1915].

Más numerosos fueron, en cambio, los trovadores que con sus canciones se enfrentaron al nuevo conde de Provenza para avivar el sentimiento y la acción de los provenzales contra el invasor. Carlos de Anjou tuvo que oir duras advertencias y crueles reproches por su desinterés por los problemas de los provenzales pues, anteponiendo a todo su ambición política y soñando con grandes proyectos de expansión, sabía que para realizarlos le hacía falta tener las arcas repletas y no derrochar el dinero siendo generoso con las cortes arruinadas y con los trovadores. A las críticas al angevino y al desánimo de los provenzales se suceden una vez más las condenas al abstencionismo de las otras potencias y, sobre todo, el de Jaime I.

Los trovadores de aquellos años, algunos nobles como Gui de Cavalhon, Bonifacio de Castellana o Bertran d'Alamanon, no solamente se comprometieron en la defensa de Provenza con sus sirventeses sino que también, algunos de ellos, empuñando las armas. También lo hicieron los trovadores de oficio adscritos a una corte determinada como Paulet de Marselha, al que quizá alguna de sus canciones pudo costarle el exilio. En sus sirventeses los caballeros-trovadores y los trovadores de oficio, increparon a los franceses y animaron a los provenzales a luchar y también a resistir; acusaron a la Iglesia, entre otras cosas, de excesiva y parcial politización; presionaron a lo sucesivos reyes de la Corona de Aragón y a los de Inglaterra recordándoles sus compromisos con frecuencia con duras palabras; silenciaron significativamente algunos nombres y personificaron actitudes políticas para que el público se identificara mejor con los partidos [M. Aurell 1989]. Porque estaba en juego su país, su lengua y sus intereses las canciones de estos trovadores son a veces vibrantes y apasionadas, desesperanzadas y amargas otras; y así se oía gritar de rabia a Bonifacio de Castellana: Lo dans dels Proensals mi platz! [102,2, Los trovadores III, 1381-1385]. Este trovador noble (..1244-1265...) fue un auténtico paladín de la independencia de Provenza y en sus sirventeses, tan belicosos, azuza a las potencias para que intervengan. En uno de ellos increpa así a Jaime I 


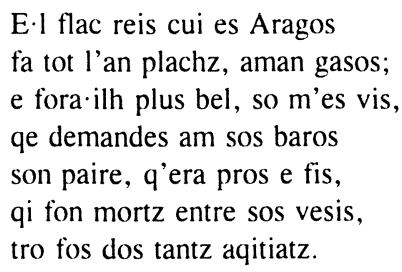

[Y el flaco rey a quien pertenece Aragón promueve pleitos todo el año y ama a los charlatanes; le sería mejor, a mi parecer, que con sus barones reivindicara a su padre que era noble y leal, y fue muerto entre sus vecinos, hasta que se hubiera resarcido dos veces] Era, pueis yverns es e $\cdot l$ fil $, 102,1$.

[Los Trovadores III, 1381]

Bonifacio de Castellana y Hug dels Baus, señor de Meirargues, capitanearon a los marselleses para que se rebelaran contra Carlos de Anjou en 1262; pero el angevino tomó Castellana, la destruyó, y luego sitió Marsella. El refugio de Bonifacio de Castellana y de los marselleses que escaparon de los soldados de Carlos de Anjou fue, primero, Montpellier, dominio de Jaime I. En su persecución Carlos de Anjou, entró en Montpellier y puso en comprometida situación al rey catalán porque por el tratado de Corbeil, 1258, se había comprometido a renunciar a toda reivindicación respecto a Provenza. Carlos de Anjou, ante las exigencias del rey, se retiró. Actuó como mediador, por encargo de su padre, el infante Jaime, a quien correspondía el señorío de Montpellier desde el 21 de agosto de 1262, fecha del último y definitivo testamento del Conquistador ${ }^{8}$. Tanto el infante Pedro como el infante Jaime no habían visto nunca con buenos ojos el abandono por parte de su padre de la herencia provenzal. En 1257, cuando el primero tendría entonces unos diecisiete años y el segundo catorce, intentaron la invasión de los territorios de Carcasona?

A Bonifacio de Castellana lo volvemos a encontrar en febrero de 1265 comiendo en casa de la infanta Constanza de Sicilia, mujer del infante

\footnotetext{
${ }^{8}$ ACA, pergamino 1720 de Jaime I, reg. 310, fol. 58; F. SOLDEVILA, Pere el Gran, II, p. 181 , recoge las reclamaciones diplomáticas de noviembre de 1262 motivadas por este hecho.

$9 "$ "Ocassione invasionis sibi facte ab infantibus regis Aragonum vel hominibus eorumdem" se dice en una carta de unos representantes del rey de Francia al senescal de Carcasona (F. Soldevila, Pere el Gran, I, p. 88).
} 
Pedro $^{10}$. La corte catalana es pues refugio de algunos de estos trovadores faiditz (proscritos) de Provenza: Guilhem de Montanhagol, Bonifacio de Castellana y Paulet de Marselha, entre otros.

Paulet de Marselha había sido trovador en la corte del vizconde de Marsella Barral dels Baus, de política afrancesada y que siguió a Carlos de Anjou a Italia en donde alcanzó grandes honores. En su corte Paulet compuso tres canciones de amor [I. de Riquer 1996]. Al no compartir la opción política de su señor o porque a éste, tan ocupado en estas delicadas cuestiones, ya no le interesaba seguir manteniendo a trovadores, Paulet pasó, en calidad de faidit a la corte catalana, pero no a la de Jaime I sino a la de su hijo el infante Pedro de Aragón. Este cambio de actitud de nuestro trovador podría verse reflejado en la retroencha Aras qu'es lo gays pascors en la que dice en una estrofa

$$
\begin{aligned}
& \text { E si.l coms, on es valors, } \\
& \text { de Proensa, pretz prezat, } \\
& \text { ma luenha de lieys, honors, } \\
& \text { non l'er, }
\end{aligned}
$$

[Y si el conde de Provenza, en quien residen el valor y el mérito apreciado, me aleja de ella, no será cosa honrosa para él]. 319,2 vv.41-44 [I. de Riquer 1979-1982; 1996].

Los elogios al conde de Provenza, Carlos de Anjou, no son más que epítetos muy frecuentes en el vocabulario cortés de los trovadores ${ }^{11}$. También Bonifacio de Castellana, del que no podemos poner en duda su aversión al angevino, le llama mon seignor y lo pros Carles, en sentido antifrástico o irónico [102, 1, Los trovadores III, 1383]. Aragón.

La tornada de esta canción de Paulet va dirigida al infante Jaime de

${ }^{10}$ F. SOldeVILA, Pere el Gran. I, pp. 196-202; J. MIRET y SANS, Itinerario del rey Alfonso I de Cataluña, II de Aragón, "BRABLB", II (1903-1904), pp. 257-278; 389-423 y 437-474.

"Tanto pretz como prezat, procedentes del sustantivo latino pretium definen una de las cualidades más específicas del vocabulario cortés y en los trovadores se emplea para calificar un rango elevado. En el cuadro de frecuencias de empleo de determinados términos corteses, pretz es el preferido por la mayoría de los trovadores por encima de valor y onor; véase G. CROPP, Le vocabulaire courtois des troubadours de l'époque classique, Ginebra, Droz, 1975, pp. 110,150 y 471 . 


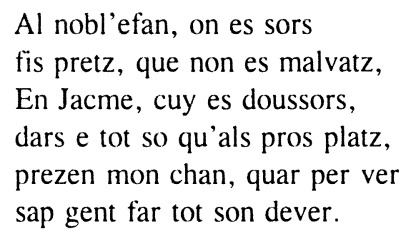

[Al noble infante don Jaime, de quien surge el leal mérito, pues no es maivado, y en quien están la dulzura, la liberalidad y todo lo que place a los más dignos, ofrezco mi canto, porque en verdad sabe cumplir gentilmente con su deber]. 319,2 vv. 51-56.

El infante Jaime de Aragón, como heredero del señorío de Montpellier, era considerado el campeón de la causa de los provenzales. Si Paulet escribió esta canción estando aún en Provenza, el ofrecimiento de esta poesía al infante Jaime pudo costarle el destierro, ya que, en aquellos momentos, exaltar el patriotismo podía suponer un grave delito contra los intereses del de Anjou y verse precisado a exiliarse, voluntariamente o a la fuerza, y siguiendo la ruta de tantos faiditz refugiarse en Cataluña. Este poema no sólo acusa el cambio de protector del trovador Paulet de Marselha sino también el de su inspiración poética: de componer canciones de amor en la corte de Barral dels Baus a figurar como juglar del infante Pedro y con sus versos ser portavoz de la política de la Casa de Aragón.

En los registros de Cancillería de la casa del infante Pedro de Aragón consta una lista de personas con la cantidad que se les asignaba al margen. Corresponde a los meses de abril y mayo de 1262 en Barcelona ${ }^{12}$. En ella encontramos

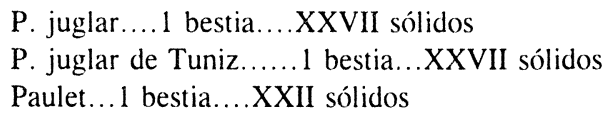

También consta una orden de pago de cincuenta sueldos por parte del tesorero del infante Pedro en Barcelona en octubre de 1267, a favor de un "juglar Paulet" [Miret i Sans 1908].

Parece pues que existe una estrecha relación entre la rebelión de los marselleses de 1261-1262, la composición Aras ques lo gays pascors en VII.

${ }^{12}$ ACA, C, reg. 27, fol. 75 v.; F. Soldevila, Pere el Gran, I, p. 72 y "Apèndix" I, doc. 
donde Paulet dice que teme ser alejado de Provenza por el conde, y la estancia documentada de este trovador en la corte del infante Pedro ya en 1262 y más tarde en 1267.

Precisamente por estar en la corte de los reyes catalano-aragoneses Paulet de Maselha no dejará de implicar a Carlos de Anjou en sus poesías, criticando su política de manera directa y clara. Con una Provenza sometida desde 1263, Carlos de Anjou llevó las fronteras del dominio francés hasta el mar Mediterráneo y ahora va a dirigir sus ambiciones hacia la conquista de Italia. Fue el único de los príncipes del occidente europeo que aceptó la invitación del papa Urbano IV a apoderarse de la herencia de los Hohenstaufen y de arrebatar así a Manfredo el reino de Sicilia. Ello hace que vuelvan a enfrentarse Francia y los reyes aragoneses y que renazca la rivalidad entre Carlos de Anjou y el infante Pedro, antes adversarios en Provenza y ahora en la sucesión de la corona de Sicilia y en las empresas mediterráneas. Carlos quería ser rey de Sicilia por la fuerza y Pedro aspiraba a heredar el trono de su suegro Manfredo por no tener éste otra heredera que Constanza Hohenstaufen.

Paulet de Marselha, a sueldo del infante Pedro de Aragón, no deja de reclamar los intereses catalanes en Provenza, y lo hace con una «pastorela», género lírico-narrativo que algunos de los último trovadores, Joan Esteve, Cerverí de Girona y Guiraut Riquier emplearon para verter ideas políticas o morales [I. de Riquer 1996, 35-38].

La pastorela $L$ 'autrier se compuso entre el 25 de abril de 1265 , inico de la campaña de Carlos de Anjou en Italia, y el 26 de febrero de 1266, batalla de Benevento, pues alude a acontecimientos acaecidos entre estas dos fechas. Reprocha Paulet duramente la política angevina y recoge los sentimientos y las ideas expresadas también por otros trovadores en sus sirventeses de marcado espíritu antifrancés y anticlerical, dos conceptos que reprsentaban entonces el rechazo de Carlos de Anjou y el apoyo a Manfredo de Sicilia [M. Aurell 1989, 165-166]. El proyecto de liberación de Provenza mediante la unión de los herederos de Cataluña y de Inglaterra en un ataque conjunto, que ya habían considerado otros trovadores, no pasaron de ser una quimera expresada en la pastorela de Paulet. Si fue compuesta en aquellos años aún vivía Jaime I que impedía a los infantes toda intervención en Provenza. 


\author{
que ja per el patz non auran \\ li sieu enemic ni perdo; \\ e.I proensal restauraran \\ per el lur barnatge, quar so \\ envejos de lui, e pres \\ lo tenon ades del cor;
}

\begin{abstract}
[Moza, respecto al infante os puedo asegurar que, si Dios le da salud y vida, con él no hallarán paz ni perdón sus enemigos; y que por él los provenzales recuperarán su nobleza, pues están deseoso de él y lo tienen siempre cerca del corazón]. L'autrier m'anav'ab cor pensiu, 319,6 vv.72-79 I. de Riquer 1996, 41-44; 102-111].
\end{abstract}

Todavía residiendo en la corte catalana un grave acontecimiento provoca una nueva poesía de Paulet de Marselha. En el sirventés $A b$ marrimen et ab mala sabensa, nuestro trovador pide insistentemente la liberación del infante Enrique de Castilla, pues cierra cada una de las cinco estrofas y las dos tornadas con el "mot-refranh" N'Enric, intencionado recurso estilístico muy utilizado por los trovadores para destacar el motivo o la intención de su canción. La enemistad con su hermano Alfonso X, sus aventuras en Túnez, su amistad y más tarde ruptura con Carlos de Anjou, su afición a la poesía y su vida inconformista y aventurera eran motivos más que suficientes para que este infante de Castilla contara con las simpatías de los trovadores. Y cuando en la batalla de Tagliacozzo se enfrentó al de Anjou del lado de los imperiales y fue hecho prisionero, muchas voces se elevaron pidiendo su liberación. El sirventés de Paulet parece ser uno de los primeros que se compusieron en la corte del infante Pedro de Aragón con motivo del encarcelamiento del infante don Enrique ${ }^{13}$.

\author{
Tug I'espanhol, del Gronh tro Compostella, \\ devon planher la preizo, que ges bella \\ non fo ni es, de N'Enric de Castella; \\ e.I reys $N^{\prime}$ Anfos, que tan gent se capdelha \\ ab sen antic \\ deu demandar tost son fraire N'Enric
}

\footnotetext{
${ }^{13}$ Este sirventés es la última composición fechable de Paulet de Marselha. Los cancioneros no registran ninguna otra poesía de este trovador y en los libros de cancillería de Pedro el Grande su nombre no vuelve a figurar (I. de RIQUER, 1996).
} 
[Todos los españoles desde Logroño hasta Compostela deben lamentar el apresamiento de don Enrique de castilla, lo que no fue ni es nada bello; y el rey don Alfonso, que tan bien se conduce con juicio maduro, debe reclamar pronto a su hermano don Enrique]. Ab marrimen et ab mala sabensa 319,1 vv. 14-19, [I. de Riquer 1996, 53-54126-129].

Dos sirventeses más que reclamaban también la liberación del Infante castellano fueron compuestos dentro del mismo ambiente, uno es del trovador Folquet de Lunel compuesto hacia 1273, y otro, el más violento de los tres, de Cerverí de Girona, compuesto entre 1272 y 1276, también acaba las cinco estrofas con el "mot-refranh" N'Anrich [M. de Riquer 1973]. A pesar de las numerosas y reiteradas súplicas que se elevaron a Carlos de Anjou el Infante don Enrique no fue liberado hasta morir el angevino veinticinco años más tarde.

Los trovadores del entorno de Jaime I tuvieron dos últimas ocasiones para componer sus canciones en torno a este monarca catalán: el proyecto de Cruzada y la muerte del rey. El cuatro de septiembre de 1269 partió Jaime I con la escuadra que pretendía reconquistar Tierra Santa, cruzada que muy pronto fracasó debido a una tormenta. Cerverí de Girona, Olivier lo Templier y Guilhem de Mur compusieron sendas canciones de cruzada con este motivo:

\author{
per que 1 rey prech d'Arago que's garnischa \\ e pas la mar per totz los tartz confondre \\ que lay son prest de nostra ley preziva \\ mermar. don dan nos sech.
}

[Por lo que ruego al rey de Aragón que se arme y atraviese el mar para destruir a todos los tártaros que allí están dispuestos a humillar nuestra preciosa ley, de lo que nos resulta daño]. Cerverí de Girona, En breu sazo aura'l jorn pretentori, 434a, 20 vv. 13-16 [Riquer 1947, 97].

Rey d'Arago, de tot mal non chalen, qu'avetz conquiat de Tortos'a Biar e Malhoga, sovenga us d'otramar, pues que autre non pot esser tenens del sieu Temple que avetz tan gen servit. E car vos es del mon lo pus ardit de fagz d'armas ni Roma vo'n covida, acorretz lai on tot lo mon vos crida. 
[Rey de Aragón, indiferente a todo daño, que habéis conquistado desde Tortosa hasta Biar y Mallorca, acordaos de ultramar, pues ningún otro puede poseer de su Templo, al que habéis servido tan bien. Y pues en el mundo sois el más valiente en hechos de armas, y Roma os incita a ello, llevad socorro allí donde todo el mundo os llama]. Olivier lo Templier, Estat aurai lonc temps en pessamen, 312,1 vv.17-24 [Los trovadores, III, 1475].

Y también Guilhem de Mur se une a este ambiente de cruzada

$$
\begin{aligned}
& \text { L'arcivesque prec de cuy es Toleta } \\
& \text { qu'amoneste lo bon rey d'Arago } \\
& \text { que per complir sos vot en mar se meta } \\
& \text { e per tener en pes son bon resso. }
\end{aligned}
$$

[Ruego al arzobispo de Toledo que amoneste al buen rey de Aragón para que entre en el mar para cumplir su voto y para seguir manteniendo su buena fama]. D'un sirventes far, 226,2, vv.41-44 [Appel, Prov. Inedita, 144].

Y Guilhem d'Autpol, en una tensó, narra el sueño que tuvo en el cual increpaba a Dios por la mala actitud de príncipes y clérigos ante el problema de las cruzadas; en la tornada hace alusión a Jaime I,

Rei d'Aragon, pair'e fil de prozeza, castel de pres, fons de so per c'om val, mon som ie-us dic, seinher, si Dieus vos sal, que 1 menares en dreg vostra franqueza.

[Rey de Aragón, padre e hijo de proeza, castillo de mérito, fuente de aquello por lo que se tiene valor, os explico mi sueño, Señor, y, si Dios os protege, con vuestra franqueza lo llevaréis derechamente a término]. Seinhos, aujas, c'aves saber e sen, 206,4 vv.69-72 [Los trovadores III, 1520].

La muerte de Jaime I acaecida el 26 de julio de 1276 fue commemorada en dos planhs. El de Matieu de Caersí, trovador del que sólo se conserva esta obra, consta de 89 versos y tiene un acusado tono moralizador y religioso; en la tornada solicita a los hijos del difunto que sigan otorgándole protección.

Ay! Aragos, Cataluenha e Serdanha 
e Lerida, venetz ab mi doler, quar ben devetz aitant de dol aver cum per Artus agron silh de Bretanha.

[iAy Aragón, Cataluña, Cerdeña y Lérida, venid a doleros conmigo, pues bien debéis tener tanto dolor como por Artús tuvieron los de Bretaña!]. Tant suy marritz que hom no.m puesc alegrar, 299,1 vv.30-33. [Los trovadores III, 1541].

Y el más importante trovador de la corte del Conquistador compone un solemne planh en el que se atiene a todos los tópicos trovadorescos propios del género, sin incluir ningún rasgo personal del difunto. Cerverí de Girona no aprovecha, o no quiere hacerlo, su estrecha relación con Jaime I para dar una imagen más personal del monarca. Se podría destacar en su planh la invocación a la Virgen en la primera tornada, propia de los trovadores tardíos [I. de Riquer 1997], que aquí es la Virgen de la Merced, cuya Orden fue fundada por iniciativa del rey,

Si per tristor, per dol ne per cossir ne per dolor nuylls hom de dol moria, eu qui sospir planyen e planc e plor, dolens, delir, penan, languen, deuria per la greu mort, dur'e mala d'auzir, per que totz homs valens tayn que s'azir, del rey Jacme, qui may que pretz valia.

Mayre de Deu, a vos deyn sovenir qu'el reys no volc anc a merce falir, e trop merce delay, pus çay l'avia.

[Si por tristeza, por congoja, por preocupación y por dolor puede alguien morir de pena, yo, que suspiro y, lamentándome, me quejo y lloro, debería fundirme, desgraciado, penando y languideciendo, por la grave muerte, dura y mala de oír, del rey Jaime, que valía más que el mérito, por lo que atañe que todo hombre valiente se apene...Madre de Dios, dignaos acordaros de que el Rey nunca quiso faltar a la piedad (merced), y encuentre allí piedad (merced), pues aquí la tenía]. Si per tristor, per dol ne per cossir, 434a, 62, vv.1-7;36-38 [Riquer 1947, 115].

Ya ha sido aquí mencionado en un par de ocasiones Cerverí de Girona (..1259-1285 ...) el gran trovador catalán de la corte de Jaime I, de quien recibió emolumentos y tierras en la actual provincia de Gerona, y que 
luego pasó a la del infante Pedro; también fue protegido por el vizconde de Cardona y vistó la corte de Castilla de Alfonso X el Sabio y la de Enrique de Rodés. Su obra conservada es la más extensa que existe de trovador alguno y abarca todos los estilos, géneros y modalidades, desde las canciones de tipo popular, como dansas, baladas, etc., a las de artificioso estrofismo o de contenido hermético, pasando por poemas didácticos y morales, canciones de amor, violentos sirventeses, poesía religiosa, coblas plurilingües, jerigonzas y unos Proverbis que firmó con su auténtico nombre, Guillem de Cervera [M. de Riquer 1947; Los trovadores III, 1556-1589].

Aquí sólo voy a considerar un aspecto del cancionero, y de la vida, de este trovador y que coincide con expresiones y sentimientos que se encuentran en otros trovadores que en algún momento tuvieron relación con él: Paulet de Marselha y Guiraut Riquier.

Estos trovadores, también de oficio, no ocultan ni disimulan en algunas de sus composiciones la inseguridad que sienten respecto a su profesión, haciendo alusión a continuas rivalidades (que siempre las había habido, pero ahora había menos demanda de trovadores), por lo que muchas de sus canciones no son lamentos retóricos por la desaparición de una "edad de oro" sino que reflejan auténtica preocupación por una situación real, de estamento y también individual, de supervivencia de su medio de vida. Esto hace que los últimos trovadores vayan pasando por las cortes que todavía se interesan por ellos: la de Jaime I y su hijo el infante Pedro, la de Alfonso $\mathrm{X}$ y algunas del sur de Francia, como las de los señores de Rodés, Narbona y Astarac o algunas del norte de Italia; y se esfuerzan por componer todo tipo de canciones en las que, además de la poética amorosa ya acuñada en los casi ciento cincuenta años de lírica trovadoresca, se vea una renovación. Debates entre tres o cuatro trovadores en los que se discute la belleza de una dama concreta o la generosidad de una determinada corte, recuperación de los géneros "popularizantes": baladas, dansas, etc., cuyas forma e inspiración proceden del norte de Francia; composiciones plurilingües, métrica rebuscada e innovadora; y poemas, sean cansos o albas, en las que la dama ha sido sustituída por la Virgen en las alabanzas del trovador. Y, sobre todo, propagando la política de sus señores. Fueron unas décadas de actividad intensa, componiendo frenéticamente y traslándose de un lugar a otro, que acabaron por la fuerza de acontecimientos externos a la práctica trovadoresca en sí.

Pero para la mayoría de estos trovadores su paso por algunas de estas cortes sólo es circunstancial, sin lograr establecerse definitivamente en 
ellas. Casi todos podrían suscribir las meláncolicas palabras de Guiraut Riquier, trop suy vengutz als derriers, «he llegado demasiado tarde» en Ben degra de chantar tener, 248,17, v. 16, [Mölk 1962, 19].

Era bien sabido que a Jaime I le gustaba rodearse de juglares y de trovadores y que algunos de ellos habían recibido tierras de las conquistadas en las expediciones militares del monarca. Guiraut Riquier, trovador narbonés (...1254-1292), intentó durante algunos años ser llamado por los sucesivos reyes catalanes, enviándoles canciones expresamente llamativas, de formas nuevas que no pasaran desapercibidas en aquella corte tan habituada a los grandes trovadores. Su primera retroencha, canción con estribillo, forma poco utilizada por los trovadores provenzales, es del año 1270 , y el estribillo que se repite a lo largo de las cinco estrofas no podía ser más halagador para la corte catalana,

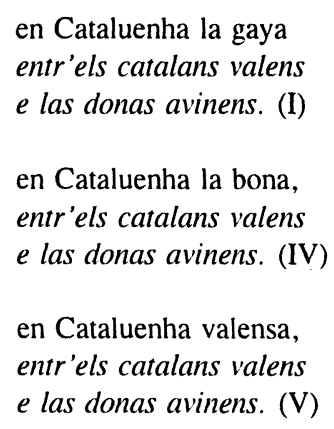

[I...en la alegre Cataluña, entre los catalanes valientes y las damas amables.IV....en Cataluña la buena, entre los catalanes valientes y las damas amables.V... ayuda en Cataluña, entre los catalanes valientes y las damas amables]. Pus astres no m'es donatz, 248,65 [Los trovadores, III, 1615].

Tampoco tuvo éxito su "canso redonda et encadenada", Pus sabers nom val ni sens, 248,66 (Mölk 1962, 103) dedicada a Lo rey, de saber paire,/ Peire d'Aragon, en 1282; canción artificiosa con la que pensó que podría interesar a un rey poeta.

Guiraut Riquier con anterioridad se había dirigido a Alfonso X cuya corte era una meta cultural; también más de veinte trovadores provenzales habían pasado por ella o la habían aludido en sus composiciones. Y también nuestro trovador había empezado enviando y dedicando al monarca 
castellano Epístolas y canciones en las que no ocultaba en ningún momento su deseo de formar parte de sus trovadores. Incluso escribió canciones dedicadas a la Virgen porque sabía que esto podría complacer al rey de las Cantigas.

Lo mismo hizo Cerverí de Girona que dedicó su Cançó de Madona Santa Maria al «Rey castellano, todo ser muere y acaba, pero ello no le ocurre a la dama que vos cantáis» $(434 \mathrm{a}, 54, \mathrm{vv} .1-2)$, cuando fue a Castilla en 1269 con el cortejo del infante Pedro.

Guiraut Riquier consiguió ir a Castilla, pasó allí diez o doce años, 1269-1281, en los que compuso veintiocho poemas de todo tipo. Pero sus canciones no son alegres, sino decepcionadas, amargas y rencorosas porque se considera mal recompensado, mal pagado.

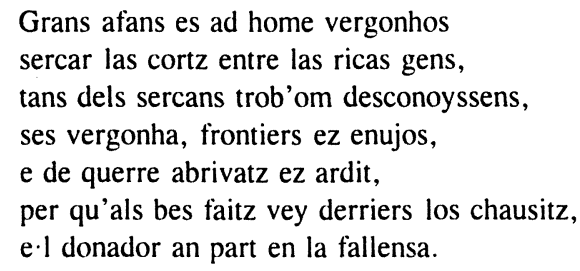

[Es duro para un hombre discreto ir de corte en corte de ricos señores; y encontrarse allí a ignorantes, atrevidos, envidiosos y audaces para exigir, mientras veo que los mejores son los últimos a los que llegan los beneficios, y los que los dan son los responsables de este error]. Grans afans es ad home vergonhos, vv.1-7. [Longobardi, 1982-1983, VI, 55].

Muy reveladora es la despedida que dedica a Alfonso X,

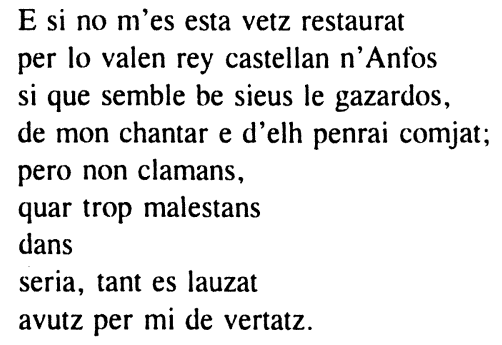

[Y como esta vez no tendré recompensa que me parezca digna del valiente rey de Castilla Alfonso, me despediré de mi canto y de él; aunque sin denunciarlo porque no sería conveniente ya que en el pasado le he alabado 
con toda verdad]. Yverns $n 0^{\bullet} m$ te de chantar embargat, vv. 37-45; [Longobardi 1982-1983, XI, 80].

En los mismos años en que transcurrían las dificultades de Guiraut Riquier para establecerse en una corte, se oían las quejas de Cerverí de Girona y su preocupación por alcanzar con su profesión un lugar honorable en la sociedad, para que su situación en la corte fuera estable, y se le distinguiera como trovador por encima de los juglares.

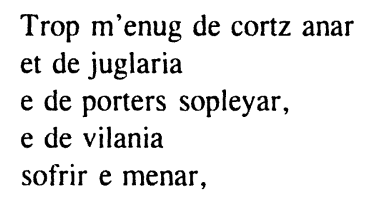

[Cuánto me molesta ir por las cortes y [hacer como] la juglaría, suplicar a los porteros y soportar y sufrir villanías»]. 434a,74, vv.1-5 [Riquer 1947, 85; HLC, I, 156-158].

A pesar de que había recibido importantes donaciones del rey Jaime, Cerverí se muestra irritado, contradictorio y amargo cuando alude al tema juglaresco. Critica a todos los juglares, en Jutglar, prec vos an, 434a, 29, al acusar a uno de ellos de que sólo sabe decir mentiras aduladoras a los ricos para tener ventajas, sólo le interesa las comidas, desconoce la fidelidad y lleva una vida vil y vergonzosa por lo que le aconseja que deje la falsa confrarya, v. 26, y le cante a la Virgen. Por el contrario, en Lo vers del saig $e$ del joglar los defiende con ingenio y habilidad aportando ejemplos de juglares famosos; y al final de la composición, que dedica al rey Pedro el Grande, manifiesta Cerverí con orgullo:

Eu no razo per mi meteus juglar ne suy juglars ne. $n$ fau captenimen, car ço qu'eu fatz fan l'aut rey entenden.

[No defiendo al juglar en atención a mí mismo: no soy juglar ni hago su oficio, porque lo que yo hago lo hacen los altos reyes entendidos].

Y en la última tornada,

Si motz laçan trobar es juglaria, eu e.l rey aut n'em juglar d'una guia. 
[Si enlazando las palabras el trobar es juglaría, yo y el alto rey somo juglares de la misma guisa]. 434a,57, vv. 31-33; 39-40 [Riquer 1947, 233].

Cerverí ha hecho alusión al rey Pedro el Grande como trovador, el rey al que Guiraut Riquier había enviado su cansó redonda. Después de Alfonso II hay otro trovador entre los reyes de Aragón y no será el último.

No era un capricho terminológico la precisión de Cerverí sino que tenía también una motivación económica y de prestigio, ya que ser trovador había de ser un oficio estable, honorable y bien retribuído. En la corte el trovador no era únicamente una distracción sino el artista que componía, que creaba motz e so, palabras y música, sin olvidar la función pedagógica para los que también quería ser trovadores. Paulet de Marselha se había mostrado muy irritado cuando, en un tornejamen, debate entre cuatro trovadores, Guiraut Riquier, que había interpelado previamente a dos grandes señores, trovadores ocasionales, sobre cuestiones de amor con damas del vecindario, le pregunta a él, trovador asalariado, si preferiría visitar la corte de Alfonso $\mathrm{X}$ o la de Manfredo de Sicilia. Paulet le contesta que prefiere la de Sicilia porque ya había estado en la del rey Alfonso, pero «otra vez dadme a escoger entre temas de amor y no de juglarías» [I. de Riquer 1996, 44-50; 114-117].

En el año 1274, Guiraut Riquier, que estaba en la corte de Alfonso $\mathrm{X}$, dirigió una Suplicatio al rey en la que le rogaba que, ya que todos los estamentos tenían su denominación particular y por lo tanto nadie confundía un «clerc» con un caballero, ni un burgués con un campesino, era necesario que determinara exactamente los nombres y las atribuciones de aquellos cuyo oficio era entretener honestamente a la gente. La Declaratio o respuesta del rey, compuesta unos años más tarde por el mismo Guiraut Riquier, aunque con las ideas y la autorización del monarca castellano, intenta resover el problema definiendo y separando cada categoría de las diferentes funciones de la juglaría del siglo XIII. Respecto a los dos términos que aquí nos interesan, la diferencia entre juglar y trovador, escribe en la Declaratio:

[ «...los que con cortesía y suficiente conocimiento se saben comportar entre los poderosos, tocando instrumentos y canciones de otro, o cantando versos y canciones de los demás y hechos ajenos, buenos y agradables de oír, bien pueden poseer el nombre de juglar;... pero son distintos de los trovadores. Éstos son los que saben hacer, con el corazón, coblas y dansas doblas, atrevidos sirventeses, albas y partimens y saben trovar palabras y sonidos y no se ocupan de ninguna otra cosa en la corte, como no sea enviar o decir 


\begin{abstract}
su saber a los más dotados. Éstos, por su justo saber, sean llamdos trovadores, sean llamados doctores de trovar los más dignos que con saber y sentido hacen versos y canciones y otras composiciones buenas, provechosas y agradables, con bellos ensenhamens; sus hechos serán muy famosos». Bertolucci 1966].
\end{abstract}

Guiraut Riquier, Cerverí de Girona e incluso Paulet de Marselha (que, aunque sin querer compararlo con estos dos grandes trovadores, había compuesto cuatro canciones de amor, una dansa, una pastorela política, un planh, un sirventés y participado en un debate con tres trovadores más, escogiendo cuidadosamente las combinaciones métricas y las rimas para no repetirse nunca), se sentían y eran trovadores por lo que se quejaban de ser acogidos en las cortes sólo de manera provisional, de depender siempre de la generosidad y del humor de los príncipes, de tener la necesidad de reclamar en lugar de ser solicitados; y, quizá, de aparecer en los libros de cuentas de la cancillería real, y ser estipendiados, como «juglar Paulet» o como «G. de Cervaria, ioculatori» 0 «mimmo» ${ }^{14}$. A pesar de la distinción entre trovador y juglar tan clara y justa establecida por el rey Alfonso X, poeta y legislador, los trovadores continuaron siendo confundidos con los juglares, en las Vidas y en los documentos de cancillería.

También podría haber otro motivo por el que Paulet de Marselha, Cerverí de Girona y Guiraut Riquier se sintieran tan molestos de que se les relacionara con la juglaría y ser llamados juglares.

En estos mismos años de la actividad de estos tres trovadores se dieron duras críticas a los juglares por parte de los moralistas [Tavani 1995]. En efecto, Thomas Cabham en su Penitentiale condena toda una serie de oficios o modos de entretener a la gente que él califica de "juglarescos", como los acróbatas, los que se disfrazan, los clérigos vagantes, los ilusionistas o los que con sus cantos mueven a los hombres a la lascivia, es decir, los juglares líricos; pero también son condenables aquellos juglares que para complacer al auditorio lanzan oprobios e ignominias sobre los ausentes. Los únicos que quedan libres de reprobación son los juglares de las gestas de los príncipes y de vidas de santos porque consuelan a los hombres en sus angustias.

Ramon Llull decía lo mismo, ensañándose con los juglares de lírica que «moven lo coratge de les fembres a puteria», y hacen a los hombres

\footnotetext{
${ }^{14}$ Miret y SanS, 1903-1904 y 1908; M. de Riquer, 1950.
} 
«altius, ergullosos, e desconeixents e deslleials»; y ampliaba el repertorio de sus condenas a todos los juglares por ser los causantes de enfrentamientos y guerras entre reyes y príncipes.

Los malvats joglars veem, Sényer, ésser maldígols e malmescladors entre entre un príncep e altre, e entre un baró e altre; e per la mala fama que sembren los joglars, e per l'oí e la mala volentat que engendren entre Is alts barons, per ço veem destruir emperis e regnats e comdats e terres, viles e castells. E doncs, Sényer, quals hómens fan tan de mal en est món com joglars? ${ }^{15}$

Parece como si Cabham y Llull estuvieran describiendo a autores de sirventeses como Bertran de Born, Guillem de Berguedà, Cerverí de Girona o algunos más de los que hemos visto páginas atrás.

A pesar de este malestar que dejan entrever los tres trovadores citados y a despecho de las censuras eclesiásticas, los sucesivos reyes catalanes y los nobles siguieron teniendo en su casa juglares, ministriles y chantres, consignando en los archivos sus nombres, salario y especialización, buscando los mejores por todas las cortes europeas, dialogando con ellos y deleitándose «perquè tristícia o ira foragiten e a tots temps se mostren pus graciosos». [Rubió [1953] 1984; Menéndez Pidal 1957; 61-66; Gómez 1979].

${ }^{15}$ R. LLULL, Libre de contemplació, cap. CXVIII, Obres Essencials, Barcelona, Editorial Selecta, 1960, II, p. 356. 


\section{BIBLIOGRAFÍA}

ANGLADE, J. ([1905]1973), Le troubadour Guiraut Riquier, étude sur la décadénce de l'ancienne poésie provençale, Burdeos-París, reimp. Ginebra.

APPEL, C. ([1890]1967), Provenzalische Inedita aus pariser Handschriften, Leipzig, 1890, reimp. Wiesbaden.

ASPERTI, S. (1995), Carlo I d'Angiò e i trovatori. Componenti "provenzali" e angioine nella tradizione manoscritta della lirica trobadorica, Ràvena.

AURell, M. (1989), La vielle et l'épée. Troubadours et politique en Provence au XIII siècle, Aubier Montaigne.

BertolucCi Pizzorusso, V. (1966), La supplica di Guiraut Riquier e la risposta di Alfonso X di Castiglia, "Studi Mediolatini e volgari", XIV.

BonI, M. (1954), Sordello, Le Poesie, «Biblioteca degli Studi mediolatini e volgari», Bolonia.

Boutière, J., A.-H. SChUTZ, I.-M. CluZEL ([1964] 1973), Biographies des Troubadours, "Les classiques d'oc», París.

CAzolari, M. (1995), I favolosi anni Settanta. Riflessioni sulla datazione di «Abril issia» di Raimon Vidal de Besalú, La narrativa in Provenza e Catalogna nel XIII e XIV secolo, pp. 83-108, Edizioni ETS, Pisa.

CluZEL, I.-M. (1957-1958), Princes et troubadours de la maison royale de Barcelone-Aragon, "Boletín de la Real Academia de Buenas Letras de Barcelona", XXVII, pp. 321-373.

Chambers, F.M. (1979), Three troubador Poems with historical overtones, "Speculum", LVI-1, pp. 42-54. 
DejeAnNe, J.M.L. ([1909] 1971), Poésies complètes du troubadour Marcabrú, «Bibliothèque Méridionale», Tolosa.

FRANK, I. (1955), Les débuts de la poésie courtoise en Catalogne et le problème des origines lyriques, "VII ${ }^{\circ}$ Congreso internacional de lingüística románica, Actas y Memorias», II, Barcelona.

GÓMEZ MunTANÉ, Ma C. (1979), La música en la Casa Real catalano-aragonesa (1336-1442).I. Historia y documentos, Antoni Bosch, s.a.

HOEPFFNER, E. (1946), L'Espagne dans la vie et dans l'oeuvre du troubadour Peire Vidal, Mélanges 1945, II, Études littéraires, Publications Fac. Lettres Univ. Strasbourg, Paris.

JEANROY, A. (1934), Un sirventés anonyme en faveur de l'infant Pierre d'Aragon, "Studi Medievali", nuova serie, vol. VII, pp. 1-7. Tolosa-París.

JEANRoy, A. (1934), La poésie lyrique des troubadours, 2 vols.

KÖHLER, E. (1969), Die Sirventese-Kanzone. "genre bâtard" oder legitime Gattung?, "Mélanges offerts à Rita Lejeune", Gembloux, I, pp. 159-183.

LONGOBARDI, M. (1982-1983), I Vers del trovatore Guiraut Riquier, "Studi Mediolatini e Volgari", XXIX.

MenÉndeZ Pidal, R. (1957), Poesía juglaresca y orígenes de las literaturas románicas, problemas de historia literaria y cultural, Instituto de Estudios Políticos, Madrid.

MilÀ Y Fontanals, M. ([1861] 1966), De los trovadores en España, «Obras de Manuel Milá y Fontanals» dirigidas por M. de Riquer, II, Barcelona. 
MIRET I SANS, J. (1903-1904), Itinerario del rey Alfonso I de Cataluña, II de Aragón, «Boletín de la Real Academia de Buenas Letras de Barcelona», II.

Miret i SANS, J.(1908), Viatges de l'infant En Pere, fill de Jaume I, en els anys 1268 i 1269, "Butlletí del Centre Excursionista de Catalunya», XVIII, pp. 171-212.

MöLK, U. (1962) Guiraut Riquier. Las Cansos. Kritischer Text und Kommentar, Heidelberg. Halle.

Pillet, A., Cartens, H. (1933), Bibliographie der Troubadours,

RAYNOUARD, M. (1816-1821), Choix des poésies originales des trobadours, 6. vols., París.

RIQUER, I. de (1979-1982), Las poesías del trovador Paulet de Marselha, «Boletín de la Real Academia de Buenas Letras de Barcelona», XXXVIII, pp. 133-205.

RIQUER, I. de (1989-1990), Giraut de Bornelh en las obras de Ramon Vidal de Besalú y Jofre de Foixà, "Boletín de la Real Academia de Buenas Letras de Barcelona», XLII, pp. 161-184.

RIQUER, I. de (1996), Paulet de Marselha: un provençal a la cort dels reis d'Aragó, La flor enversa, Columna, Barcelona.

RIQUER, I. de (1997), Los planhs por la (falsa) muerte de Jaufré, "Mélanges de Philologie Médiévale offerts à M-R. Jung», Edizioni dell'Orso, Alessandria.

RIQUER, M. de (1947), Obras completas del trovador Cerveri de Girona, Barcelona, Instituto Español de Estudios Mediterráneos.

RIQUER, M. de (1950), La personalidad del trovador Cerverí, «Boletín de la Real Academia de Buenas Letras de Barcelona», XXIII, pp. 91-107. 
RiQueR, M. de (1964) Història de la Literatura Catalana, I, Barcelona, Ariel.

RIQUER, M. de (1973) Il significato politico del sirventese provenzale, Concetto, storia, miti e immagini del Medio Evo, Venecia [versión española en "Miscellanea Barcinonensia", XII, 1973, pp. 7-27].

RIQUER, M. de (1975) Los trovadores. Historia literaria y textos, 3 vols., Barcelona, Planeta.

RUBió I BALAGUER, J. ([1953] 1984), Història de la Literatura catalana, I, Publicacions de l'Abadia de Montserrat.

RuIZ DoMÈnEC, J.E. (1996) A propósito de Alfonso, rey de Aragón, conde de Barcelona y marqués de Provenza, Real Academia de Buenas Letras de Barcelona, Servei de Publicacions de la Universitat Autònoma de Barcelona, Barcelona.

Soldevila, F. (1950-1956), Pere el Gran. Primera part: l'Infant, 3 vols., Institut d'Estudis Catalans.

STRONSKI, S. (1910), Le troubadour Folquet de Marseille, Cracovia.

TAVANI, G. (1995), Els trobadors catalans, Les jongleurs en spectacle, «Versants», 28, pp. 131-152.

\section{RÉSUMÉ}

La présence de troubadours provençaux dans la Couronne d'Aragon a été incessante dès le début de ce particulier mouvement poétique; les rois catalans ont été ceux qui ont accueilli dans leur cour les derniers de ces professionnels.

Les troubadours qui se sont réunis autour du roi Alphonse II d'Aragon ou ceux qui de loin, l'ont nommé dans leurs chansons, sont devenus les partisans de sa politique ultrapyrénéenne, ce qui n'a pas empéché que, dans d'autres occasions, ils se soient manifestés avec séverité contre certaines attitudes du monarque. Ils ont agi, donc, comme chroniqueurs des événements historiques et ménagers de leur temps, au moyen de poèmes d'une haute exigence artistique. 
Après l'âge d'or de l'activité des troubadours, qui coïncide avec le règne du roi Alphonse, son petit-fils Jacques I est mentionné, dès sa propre cour ou dès l'autre côté des Pyrénées, par plus d'une vingtaine de troubadours et jongleurs, entre 1213 -à peu près- et 1276, année du décès du roi. Les affaires intérieures de son royaume, ses rapports avec la cour castillane, sa passivité devant l'invasion de Provence par la maison de France, le projet de Croisade de l'année 1269 et sa mort, sont des événements qui peuvent être suivis au détail à travers les sirventes.

Aussi dans certaines chansons les troubadours d'office de cette deuxième moitié du XIII ${ }^{e}$ siècle ne cachent ni ne dissimulent pas l'insécurité qu'ils éprouvent par rapport à son métier, en faisant des allusions à de continuelles rivalités qui montent leur souci pour le maintien de leur moyen de vie. Paulet de Marselha, Guiraut Riquier et Cerverí de Girona, parmi d'autres, se plaignent de ne pas être accueillis dans les cours que de façon provisionnelle, de dépendre toujours de la génerosité et de l'humeur des princes, d'avoir le besoin de réclamer au lieu d'être recherchés, et, peut être, d'apparaître dans les livres de comptes de la chancellerie royale, et d'être rémunérés, comme "juglar Paulet" ou comme "G. de Cervaria, ioculatori" ou "mimmo", au lieu d'être nommés troubadours, métier qui avait été si soigneusement décrit par Alphonse $\mathrm{X}$ le Sage. Il porrait y avoir aussi une autre raison pour laquelle ils éprouvent de l'ennui de se voir en rapport avec la jonglerie. Dans cette même époque des écrivains moralistes comme Thomas de Cabham ou Ramon Llull lancent des critiques si dures et directes contre les jongleurs et leurs compositions, qu'il paraît qu'ils fassent des allusions à des sirventes de troubadours comme Bertran de Born, Guillem de Berguedà, Cerverí de Girona ou d'autres parmi ceux qui sont récueillis dans cet article.

\section{SUMMARY}

The presence of troubadours at the Crown of Aragon was constant since the beginnings of this original poetic movement, and the Catalonian kings were the ones who sheltered the last members of this profession.

Troubadours gathered around King Alfonso the II of Aragón (or other troubadours who, from far away places, mentioned him in their poems), became strong supporters of the King's policy beyond the Pyrenees. Nevertheless these same troubadours didn't hesitate in criticizing several other attitudes of their Monarch. Therefore they acted as chroniclers of historical and domestic events of their time through highly artistic poems.

After the golden age of the troubadours, that concurs with the kingdom of King Alfonso, his grandchild Jaime $I$ is mentioned (from his own Court or from the other side of the Pyrenees) by more than twenty troubadours or minstrels between around 1213 and 1276 , year in which the King died. The internal affairs of his kingdom, his relationship with the Castillian Court, his passive attitude concerning the invasions of Provenç by the French king, his projected Crusade in 1269 and his death, are all events that can be found precisely recorded in the sirventeses of these poets.

Some of these songs written by professional troubadours in the second half of the XIIth century, show very clearly how they are not trying to conceal nor disguise the lack of confidence they feel concerning their profession. And they do so by mentioning the persistent rivalries among themselves, something that can be interpreted as a manifestation of their 
concern about the survival of their profession. Paulet de Marselha, Guiraut Riquier and Cerverí de Girona, among others, are constantly complaining of being offered only temporary shelter in the Courts, of always having to depend on the generosity and the mood of the Princes, of always having to request instead of being requested and, sometimes, of showing in the accounting roster of the Royal House as "juglar Paulet", as "G. de Cervaria, ioculatori" or as "mimmo", instead of being called troubadours, a profession so carefully defined by king Alfonso $\mathrm{X}$ el Sabio. They probably found another reason to feel afflicted in the fact of being connected with the minstrels. In those same years some moralist writers like Thomas de Cabham or Ramon Llull casted such direct and strong criticism on the minstrels and their compositions that seemed that they were referring to some sirventeses written by troubadours like Bertran de Born, Guillem de Berguedà, Cerverí de Girona or some other troubadoursd mentioned in this paper. 